\title{
Relationship Between Interleukin 33 and Tissue Factor in Non-Diabetic and Diabetic Obese Patients
}

Cagri CAKICI ${ }^{*}$, Turkan YIGITBASI ${ }^{1}$, Maide Hacer ALAGOZ², Pakize YIGIT $^{3}$, Nesrin EME$\mathrm{KLI}^{1}$

1 Department of Biochemistry, Faculty of Medicine, Istanbul Medipol University, Istanbul, Turkey

2 Department of Clinical Biochemistry, Cekirge Devlet Hastanesi, Bursa, Turkey

3 Departmant of Department of Biostatistics and Medical Informatics, Faculty of Medicine, Istanbul Medipol University, Istanbul, Turkey

\begin{abstract}
The aim of the study is to investigate the relationship between tissue factor (TF) and Interleukin-33 (IL-33) and biochemical parameters in diabetic obese and non-diabetic obese patients. 21 healthy controls, 25 non-diabetic and 36 diabetic-obese patients were included in the study. While there was no difference between the groups in terms of IL-33 levels ( $\mathrm{p}>0.05$ ), TF levels of diabetic obese group were statistically significantly higher than control group ( $\mathrm{p}<0.05$ ). HDL levels of the obese and diabetic obese groups were significantly lower than control group, and triglyceride, glucose, insulin, C-reactive protein (CRP), hemoglobin A1c (HbA1c), and HOMA-IR levels were significantly higher $(\mathrm{p}<0.05)$. A positive correlation was found between TF activity, and HbA1c and glucose levels ( $\mathrm{p}<0.05$ ). This suggests that TF may be predictive for diabetes which develop in the background of obesity, and that TF can be used as a prognostic value for diabetes.
\end{abstract}

Key words: Diabetes Mellitus, interleukin 33, obesity, tissue factor

\section{INTRODUCTION}

Obesity is a chronic disease which is caused by disruption of energy balance, and characterized by increased body fat mass ${ }^{1}$. Adipose tissue with chronic lowgrade inflammation can contribute to the metabolic consequences of obesity.

\footnotetext{
${ }^{\star}$ Corresponding Author: Cagri Cakici, e-mail: ccakici@medipol.edu.tr ORCIDs:

Cagri Cakici

Turkan Yigitbasi

Maide Hacer Alagoz

Pakize Yigit: https

Nesrin Emekli

: https://orcid.org/0000-0002-8662-5284

: https://orcid.org/0000-0002-0675-1839

: https://orcid.org/0000-0003-2032-6684

: //orcid.org/0000-0002-5919-1986

: https://orcid.org/0000-0002-0109-5086

(Received 06 February 2021, Accepted 16 April 2021)
} 
Therefore, obesity thought to play a role in both atherosclerosis and diabetes development $^{2}$.

Diabetes Mellitus (DM) is a metabolic disease of multiple etiologies. It is characterized by chronic hyperglycemia with impaired carbohydrate metabolism, due to insulin secretion and / or defects in its progression ${ }^{3}$.

Despite various studies, the increased rate of obesity and health problems due to obesity comorbidities such as cardiovascular diseases and health expenditures are gradually increased ${ }^{4}$.

It is observed that patients, whose body mass index (BMI) remain over $30 \mathrm{~kg} /$ $\mathrm{m}^{2}$ more for than ten years, are twice as much susceptible to the risk of diabetes compared to the those with the same BMI for five years ${ }^{2}$. Type 2 Diabetes Mellitus (T2DM), which is typically caused by obesity, is the most common disease among carbohydrate metabolism disorders ${ }^{4}$. Because of this close relationship between diabetes and obesity, the concept of "diabesity" was coined. "Diabesity" is a term which refers to diabetes occurring in the context of obesity ${ }^{2}$.

Besides requiring lifelong treatment, DM also negatively affects quality of life because of acute and chronic complications ${ }^{4}$. Uncontrolled DM is the cause of multiple organ damage as a result of macrovascular and microvascular complications. It also increases the risk of cardiovascular disease by twice ${ }^{5}$.

$\mathrm{TF}$, also known as factor III or thromboplastin, is the primary initiator of the extrinsic blood coagulation system ${ }^{6}$. TF is expressed by epithelial cells around the blood vessels, such as adventitial fibroblasts, and plays a critical role in hemostasis. TF also contributes to various forms of thrombosis. Besides these well-known features, TF is highly expressed in many types of cancer, especially adenocarcinomas ${ }^{7}$. It is known that TF levels, which are also associated with increased appetite, decrease as a result of weight loss in obesity. It reduces circulating prothrombotic marker levels, including TF and plasminogen activator inhibitor-1 (PAI-1) $)^{8,9}$.

Interleukin 33 (IL-33), which is a nuclear associated cytokine and the ligand of the ST2 receptor, belongs to the interleukin 1 (IL-1) family. It is abundantly expressed in endothelial cells, epithelial cells and fibroblast-like cells, during homeostasis and inflammation ${ }^{10}$. Studies have shown that IL-33 modulates inflammatory diseases such as arthritis and atherosclerosis, as well as other inflammatory diseases of the gastrointestinal, and the respiratory systems. At the same time, both IL-33 and ST2 are abundantly expressed in human atherosclerotic plaques ${ }^{11}$. Besides, it was found that both IL-33 and ST2 are expressed in adipocytes and adipose tissues. IL-33 was found to have a protective effect in 
adipose tissue inflammation during obesity, in that it induces the production of Th2 cytokines (IL-5 and IL-13), reduces lipid storage, inhibits adipogenesis and promotes lipolysis. In addition, the treatment of obese diabetic (ob/ob) mice with IL-33 has led to protective metabolic effects such as significantly lower adiposity, lower fasting glucose, and increased glucose and insulin sensitivity ${ }^{12}$.

It is shown that IL-33 induces TF expression depending on the ST2 receptor and the NF- $\kappa$ B pathway human umbilical vein endothelial cells (HUVECs) and coronary artery endothelial cells (HCAECs) ${ }^{11}$.

However, the relationship between IL-33 and TF in non-diabetic and diabetic obese patients, and their association with other metabolic parameters have not yet been revealed. Therefore, the aim of this study is to investigate the relationship between TF and IL-33 in diabetic and non-diabetic obese patients.

\section{METHODOLOGY}

Ethics committee approval was obtained from the Istanbul Medipol University Non-Interventional Clinical Research Ethics Committee (Decision No: 335).

21 healthy controls, 25 non-diabetic obese and 36 diabetic-obese patients who applied to Istanbul Medipol Mega Hospital Biochemistry Laboratory were included in the study. BMI is a person's weight in kilograms divided by the square of body height in meters $\left(\mathrm{kg} / \mathrm{m}^{2}\right)$. Patients with BMI values ranging between 18.9 and $24.9 \mathrm{~kg} / \mathrm{m}^{2}$ were considered normal, while patients with BMI values greater than $24.9 \mathrm{~kg} / \mathrm{m}^{2}$ were considered obese ${ }^{13}$. Diagnosis of diabetes was identified based on clinical and laboratory findings according to the American Diabetes Association (ADA) criteria, HbA1c levels above $6.5 \%$ were included in the diabetic obese group, and the others were included in the non-diabetic obese group ${ }^{14}$.

Exclusion criteria were; being under 18 years old, being over 75 years old, smoking, having hypertension, heart disease, polycystic ovarian disease, inflammation, and infection.

\section{Blood collection and storage}

After obtaining consent forms from selected reference individuals, blood samples were collected between o8:00-12:00 in the morning, at the end of 8-12 hours of fasting. Blood samples were taken from the antecubital vein in a sitting position into 8-milliliter vacuum gel red-capped tubes. The blood samples were centrifuged at $3000 \mathrm{rpm}$ for 10 minutes with the NUVE (NF-80oR) brand centrifuge in the clinical biochemistry laboratory, and serum samples were separated. The separated serum samples were taken into Eppendorf tubes and stored at $-80^{\circ} \mathrm{C}$ until study. 


\section{Parameters examined in serum}

IL-33 and TF serum concentrations were measured using the ELISA method (Cusabio Elisa kit, catalog no: CSB-E130ooh and catalog no: CSB-Eo7913h, respectively). The $R$-square $\left(R^{2}\right)$ values were calculated as 0.97 and 0.99 respectively on the standard graph created to reflect the results of the measurements. The measurements were taken using BioTek Synergy HTX multimode reader. Glucose, insulin, TC, HDL, LDL, and TG serum concentrations were measured using Roche / Hitachi $\mathrm{C}_{5} \mathrm{O} 1$ autoanalyzer, with a commercial kit by a photometric method. Serum concentrations of HbA1c and CRP were measured by Roche / Hitachi Cobas autoanalyzer using a commercial kit by an immune chemiluminescence method. Insulin resistance was calculated using the formula; $($ HOMA-IR $)=[$ fasting insulin X glucose $] / 22.5^{15}$.

\section{Statistical Analysis}

SPSS 22 (IBM, Chicago) software was used for statistical analysis. The results are presented as mean values \pm standard deviations $(\overline{\mathrm{x}} \pm \mathrm{SD})$. T-test was used to compare parameters of obese and control groups which exhibit a normal distribution, and the Mann-Whitney U test was used to compare two groups which do not exhibit a normal distribution. One-way analysis of variance (ANOVA) was used to compare the differences of variables in subgroup analysis. Kruskal Wallis and Post-hoc Dunn tests were also used for parameters which did not exhibit normal distribution. The correlation graphs were created using the SPSS software and the bar graphs were created using the Graphpad Prism 8 software. The significance level was accepted as $p<0.05$ for all tests.

\section{RESULTS AND DISCUSSION}

IL-33 is a proinflammatory cytokine from the IL-1 family, which is located in the homeostatic system and is a ST2 receptor ligand. In the animal study, it was revealed that the IL-33 / ST2 effect played a role in the modulation of obesity, insulin resistance, and inflammatory pathologies of $\mathrm{T}_{2} \mathrm{DM}^{16,17}$.

Elevated levels of TF are found in atherosclerotic plaques, and TF triggers thrombosis after plaque rupture. It is known that IL-33 is expressed in atherosclerotic plaques and endothelial cells. Also, endothelial cells and atherosclerotic plaques are involved TF secretion ${ }^{11}$. Because of this connection, the relationship between IL-33 and TF was the subject of two research studies by Stojkovic et al. ${ }^{11,18}$.

In the first study, Stojkovic et al. used HUVECs and HCAECs cell lines to demonstrate that IL-33 induces TF expression of the ST2 receptor and the NF- $\mathrm{k}$ B pathway, and promotes TF activity in microparticles produced from endothelial cells. Moreover, the researchers found a positive correlation between the 
expression of TF mRNA and IL-33 mRNA in human carotid atherosclerotic plaques ${ }^{11}$. In the second study, Stojkovic et al. demonstrated that the effects of IL-33 on TF expression are related to the amounts of ST2 receptors on the monocyte surface ${ }^{18}$.

This is the first study to investigate the relationship between serum IL-33 and $\mathrm{TF}$ in non-diabetic obese and diabetic obese study groups.

As shown in Table 1, the obese group had significantly higher levels of serum TF compared to the control group ( $\mathrm{p}<0.05$ ), whereas IL-33 values showed no difference between the two groups ( $p>0.05)$. Comparing the obese group to the control group; HDL levels are significantly lower, while TG, Glucose, insulin, CRP, Hb1Ac and HOMA-IR values were higher ( $\mathrm{p}<0.05)$. There was no difference between total cholesterol and LDL levels between the two groups ( $\mathrm{p}>$ o.05) (Table 1) (Figure 1).

Table 1. Biochemical parameters of obese and control groups

\begin{tabular}{|c|c|c|c|}
\hline & $\begin{array}{l}\text { Control Group } \\
\qquad(n=21)\end{array}$ & $\begin{array}{l}\text { Obese Group } \\
\qquad(n=61)\end{array}$ & \multirow{2}{*}{$\mathbf{P}^{*}$} \\
\hline & $\overline{\mathrm{x}} \pm \mathrm{SD}$ & $\overline{\mathrm{x}} \pm S D$ & \\
\hline BMI $\left(\mathrm{kg} / \mathrm{m}^{2}\right)$ & $23,44 \pm 0,84$ & $33,75 \pm 6,15$ & $<0,05$ \\
\hline $\mathrm{TF}(\mathrm{pg} / \mathrm{ml})$ & $53,14 \pm 24,75$ & $71,90 \pm 34,51$ & $<0,05$ \\
\hline IL-33 (pg/ml) & $5,22 \pm 1,58$ & $5,54 \pm 2,02$ & $>0,05$ \\
\hline Glucose (mg/dl) & $102,69 \pm 17,22$ & $151,96 \pm 69,05$ & $<0,05$ \\
\hline HDL (mg/dl) & $53,86 \pm 10,00$ & $47,21 \pm 9,08$ & $<0,05$ \\
\hline LDL (mg/dl) & $121,52 \pm 18,36$ & $121,98 \pm 27,41$ & $>0,05$ \\
\hline $\mathrm{TG}(\mathrm{mg} / \mathrm{dl})$ & $119,73 \pm 28,68$ & $158,10 \pm 51,44$ & $<0,05$ \\
\hline TC (mg/dl) & $192,57 \pm 24,17$ & $198,35 \pm 31,96$ & $>0,05$ \\
\hline Insulin $(\mu \mid \mathrm{U} / \mathrm{ml})$ & $9,70 \pm 3,01$ & $17,21 \pm 8,53$ & $<0,05$ \\
\hline $\mathrm{CRP}(\mathrm{mg} / \mathrm{l})$ & $3,55 \pm 2,71$ & $7,73 \pm 6,98$ & $<0,05$ \\
\hline HbA1c (\%) & $5,42 \pm 0,52$ & $6,86 \pm 1,68$ & $<0,05$ \\
\hline HOMA-IR & $2,43 \pm 0,76$ & $6,40 \pm 7,46$ & $<0,05$ \\
\hline
\end{tabular}

Abbreviations: BMI: Body mass index; TF: Tissue factor; IL-33: Interleukin 33; HDL: High density lipoprotein; LDL: Low density lipoprotein; TG: Triglyceride; TC: Total Cholesterol; CRP: C reactive protein; HbA1c: Hemoglobin A1c; HOMAIR: Insulin resistance. ${ }^{*} \mathbf{p}<\mathbf{0 , 0 5}$ was considered statistically significant. 

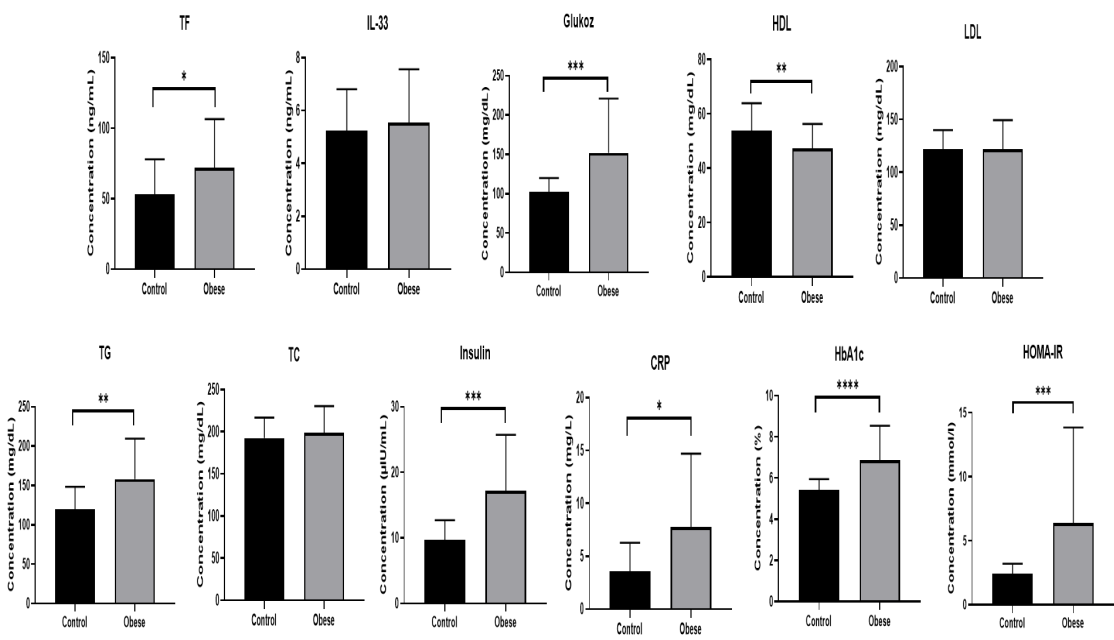

Figure 1: The bar graphs of parameters that show statistical significance in obese and control groups.

Abbreviations: TF: Tissue Factor; IL-33: Interleukin 33; HDL: High density lipoprotein; LDL: Low density lipoprotein; TG: Triglyceride; TC: Total Cholesterol; CRP: C reactive protein; HbA1c: Hemoglobin A1c; HOMA-IR: Insulin resistance. Statistical significances are indicated by asterisks. ${ }^{*} \mathbf{p}<\mathbf{0 , 0 5}$; ${ }^{* *} \mathbf{p}<\mathbf{0 , 0 1}$; ${ }^{* * *} \mathbf{p}<\mathbf{0 , 0 0 1} ;{ }^{* * * *} \mathbf{p}<\mathbf{0 , 0 0 0 1}$.

Obesity contributes to the development of diabetes and being obese generally aggravates the prognosis of diabetes ${ }^{19}$. In obesity, inflammation and metabolic changes lead to an increase in TF expression in adipose tissue and macrophages ${ }^{9}$. Confirming our findings, Ayer et al. observed that TF increased in obese patients $^{20}$. In other studies, it was revealed that thrombin formation and TF levels decreased significantly when obese individuals with loose weight ${ }^{21,22}$. Singh et al. showed that TF levels increased in the circulation system during childhood obesity and high levels of TF increased risk of cardiovascular diseases ${ }^{23}$. Studies with obese mice report that there is increased expression of TF mRNA in adipocytes as well as in adipose tissue stromal vascular cells. In addition, there was also increased TF activity in the circulation system and adipose tissue ${ }^{9,24}$.

The protective role played by IL-33 against obesity-related inflammation, insulin resistance, and T2DM was also demonstrated in animal studies. However, a limited number of human studies on IL 33 levels in obesity are controversial ${ }^{25,26}$. Similar to our results, a study done by Zeyda et al., showed no significant changes in IL-33 levels, but a significant increase in sST2 levels in 
morbidly obese subjects ${ }^{25}$. Tang et al. study's showed that serum IL-33 levels were increased in overweight/obese Chinese population. Increased IL-33 levels have positive correlation with metabolic syndrome ${ }^{27}$. In the other study, IL-33 levels were found to be lower compared to the overweight and obese groups ${ }^{26}$. It was inferred that the high IL-33 levels were due to the protective effect of IL-33 against obesity ${ }^{28,29}$.

CRP levels were found to be higher than those of the control group, which underlies inflammation in obesity. In obese individuals, there has been a relationship between CRP levels and basal peripheral blood mononuclear cell TF procoagulant activity which suggests a link between inflammation brought by obesity and thrombosis ${ }^{20}$.

When the control, non-diabetic and diabetic obese groups are compared; TF values were examined, and a statistically significant increase was observed in the diabetic obese group compared to the control group ( $\mathrm{p}<0.05)$. Although the TF levels were numerically higher in the non-diabetic obese group compared to the control group, there was no statistical significance ( $p>0.05$ ). In IL33 levels; there was no significant difference between the control, non-diabetic obese, and diabetic obese groups ( $p>0.05$ ). In the non-diabetic obese group, Insulin and CRP levels were found to be significantly higher than control group ( $\mathrm{p}<0.05$ ). In addition, in the diabetic obese group, glucose, TG, insulin, CRP, Hb1Ac, and HOMA-IR levels were significantly higher, and HDL was significantly lower than in the control group ( $\mathrm{p}<0.05)$. There was no difference in TC and LDL levels ( $>>0.05$ ). In the diabetic obese group, Hb1Ac and glucose levels were significantly higher than in the non-diabetic obese group $(\mathrm{p}<0.05)$ (Table 2) (Figure 2). 
Table 2. Biochemical parameters of control, non-diabetic and diabetic obese groups

\begin{tabular}{|c|c|c|c|c|c|}
\hline & $\begin{array}{c}\text { Control (1) } \\
n=21\end{array}$ & $\begin{array}{c}\text { Non-Diabetic } \\
\text { Obese (2) } \\
n=25\end{array}$ & $\begin{array}{c}\text { Diabetic } \\
\text { Obese (3) } \\
n=36\end{array}$ & \multirow[t]{2}{*}{$\mathbf{P}^{*}$} & \multirow{2}{*}{$\begin{array}{l}\text { *Intergroup } \\
\text { Significance }\end{array}$} \\
\hline & $\bar{x} \pm S D$ & $\bar{x} \pm S D$ & $\bar{x} \pm S D$ & & \\
\hline BMI $\left(\mathrm{kg} / \mathrm{m}^{2}\right)$ & $23,44 \pm 0,84$ & $33,91 \pm 4,64$ & $33,65 \pm 7,07$ & $<0,05$ & $1-3 ; 1-2$ \\
\hline TF (pg/ml) & $53,14 \pm 24,75$ & $64,01 \pm 32,95$ & $77,38 \pm 34,95$ & $<0,05$ & $1-3$ \\
\hline IL-33 (pg/ml) & $5,22 \pm 1,58$ & $5,70 \pm 2,02$ & $5,43 \pm 2,04$ & $>0,05$ & - \\
\hline $\begin{array}{l}\text { Glucose (mg/ } \\
\text { dl) }\end{array}$ & $102,69 \pm 17,22$ & $100,40 \pm 7,84$ & $187,76 \pm 70,10$ & $<0,05$ & $1-3 ; 2-3$ \\
\hline $\mathrm{HDL}(\mathrm{mg} / \mathrm{dl})$ & $53,86 \pm 10,00$ & $49,60 \pm 9,86$ & $45,54 \pm 8,22$ & $<0,05$ & $1-3$ \\
\hline LDL (mg/dl) & $121,52 \pm 18,36$ & $123,86 \pm 30,08$ & $120,67 \pm 25,75$ & $>0,05$ & - \\
\hline $\mathrm{TG}(\mathrm{mg} / \mathrm{dl})$ & $119,73 \pm 28,68$ & $151,01 \pm 51,84$ & $163,03 \pm 51,31$ & $<0,05$ & $1-3$ \\
\hline TC (mg/dl) & $192,57 \pm 24,17$ & $196,12 \pm 33,22$ & $199,90 \pm 31,43$ & $>0,05$ & - \\
\hline $\begin{array}{c}\text { Insulin ( } \mu \text { IU/ } \\
\mathrm{ml})\end{array}$ & $9,70 \pm 3,01$ & $16,85 \pm 8,54$ & $17,46 \pm 8,64$ & $<0,05$ & $1-2 ; 1-3$ \\
\hline CRP (mg/l) & $3,55 \pm 2,71$ & $7,21 \pm 6,60$ & $8,47 \pm 7,57$ & $<0,05$ & $1-2 ; 1-3$ \\
\hline HbA1c (\%) & $5,42 \pm 0,52$ & $5,37 \pm 0,42$ & $7,89 \pm 1,43$ & $<0,05$ & $1-3 ; 2-3$ \\
\hline HOMA-IR & $2,43 \pm 0,76$ & $4,00 \pm 2,32$ & $8,06 \pm 9,20$ & $<0,05$ & $1-3$ \\
\hline
\end{tabular}

Abbreviations: BMI: Body mass index; TF: Tissue factor; IL-33: Interleukin 33; HDL: High density lipoprotein; LDL: Low density lipoprotein; TG: Triglyceride; TC: Total Cholesterol; CRP: C reactive protein; HbA1c: Hemoglobin A1c; HOMA-IR: Insulin resistance. ${ }^{*} \mathbf{p}<\mathbf{0 , 0 5}$ was considered statistically significant. 

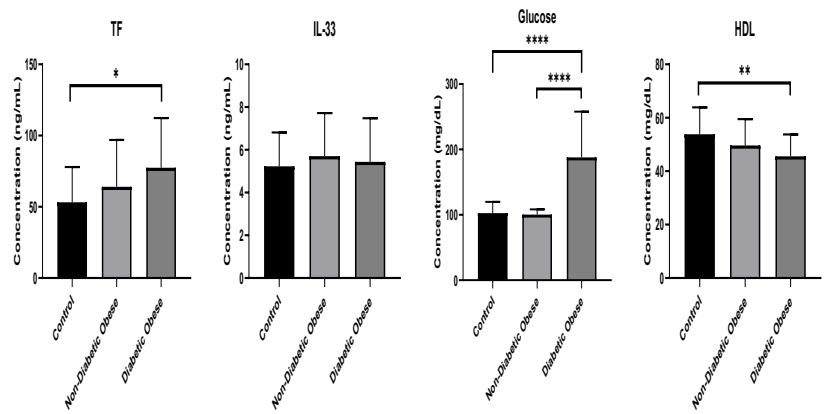

LDL
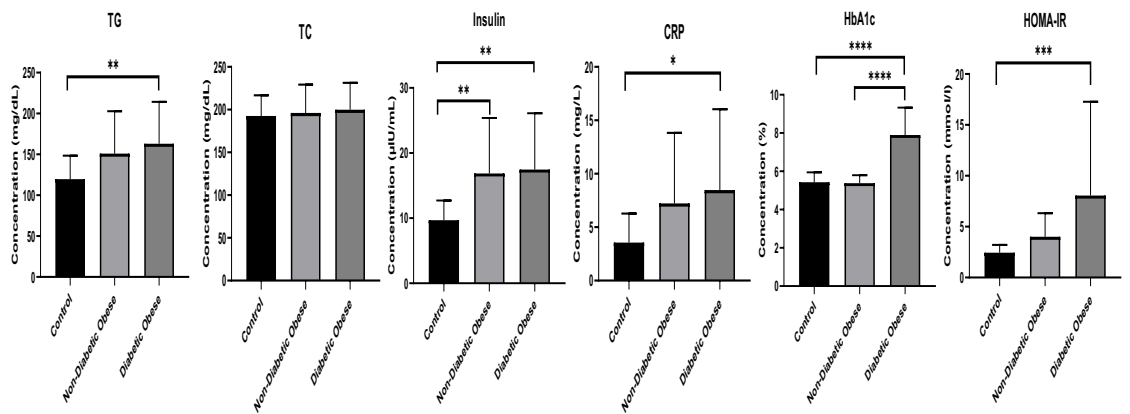

Figure 2: The bar graphs of statistically significant parameters in control, non-diabetic obese and diabetic obese groups.

Abbreviations: TF: Tissue Factor; IL-33: Interleukin 33; HDL: High density lipoprotein; LDL: Low density lipoprotein; TG: Triglyceride; TC: Total Cholesterol; CRP: C reactive protein; HbA1c: Hemoglobin A1c; HOMA-IR: Insulin resistance. Statistical significances are indicated by asterisks. ${ }^{*} \mathbf{p}<\mathbf{0}, \mathbf{0 5}$; ${ }^{* *} \mathbf{p}<\mathbf{0}, \mathbf{0 1} ;{ }^{* * *} \mathbf{p}<\mathbf{0 , 0 0 1 ;}{ }^{* * * *} \mathbf{p}<\mathbf{0}, \mathbf{0 0 0 1}$.

In the study comparing diabetic obese and non-diabetic obese groups, plasma TF antigen, activity, and adipose tissue TF mRNA were found to be higher in the diabetic obese group in comparison to the non-diabetic obese group ${ }^{30}$. A study on patients with T2DM found that in cases where hyperglycemia and hyperinsulinemia exist together, there is increased expression of monocyte TF as well as increased platelet interaction with monocytes. Hyperglycemia and hyperinsulinemia alone also stimulate platelet activation, and monocyte TF expression is increased by selective hyperinsulinemia ${ }^{31}$. As reported by previous studies, the prevalence of thrombosis is high among diabetes patients and these patients also exhibit high TF activity ${ }^{32,33,34,35,36}$. In diabetic obese group, high TF levels were the result of inflammation, hyperlipidemia, hyperglycemia, and hyperinsulinemia ${ }^{37}$. 
The effect of IL-33 on TF protein production and TF activity was also concentration-dependent, whereby substantial effects were observed at concentrations > $0.1 \mathrm{ng} / \mathrm{mL}$ in both HUVECs and HCAECs ${ }^{11}$. In our study no correlation was observed between IL-33 and TF for both the diabetic obese and non-diabetic groups. In the other study, it was found that different layers of monocytes have different amounts of ST2 receptors, and the effect of IL-33 depends on ST2 receptor density ${ }^{18}$.

In our study, IL-33 levels were measured in serum. It can be inferred that IL33 concentration can modulate TF expression and activity in local tissue or the amount of ST2 receptor density in endothelial cells ${ }^{11}$.

Upon examination of the HOMA-IR values, a twofold increase was observed in the diabetic obese group compared to the non-diabetic obese group. It was then deduced that compensatory hyperinsulinemia associated with T2D contributed to the increase in plasma TF expression in these patients.

TF was positively correlated with glucose $(r=0.285 ; \mathrm{p}<0.05)$ and HbA1c ( $\mathrm{r}$ $=0.226 ; \mathrm{p}<0.05)(\mathrm{p}<0.05)$. There was a strong positive correlation between glucose and HbA1c $(r=0.734$; $p<0.01)(p<0.05)$. However, there was no correlation between TF and IL-33 (Figure 3-4).

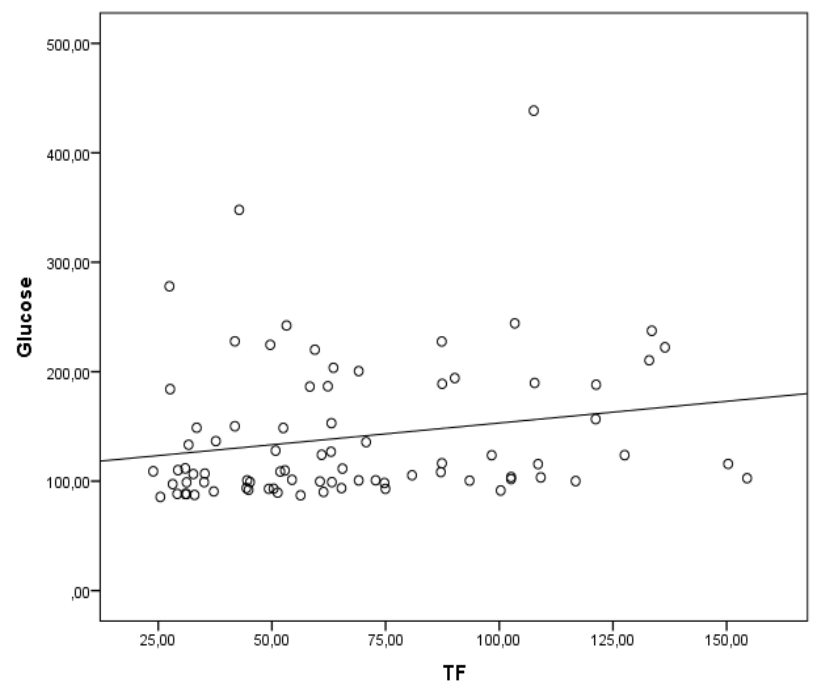

Figure 3: Correlation graph between TF and glucose. Serum levels of TF were correlated with serum levels of glucose $(r=0.285 ; p<0.05)$. 


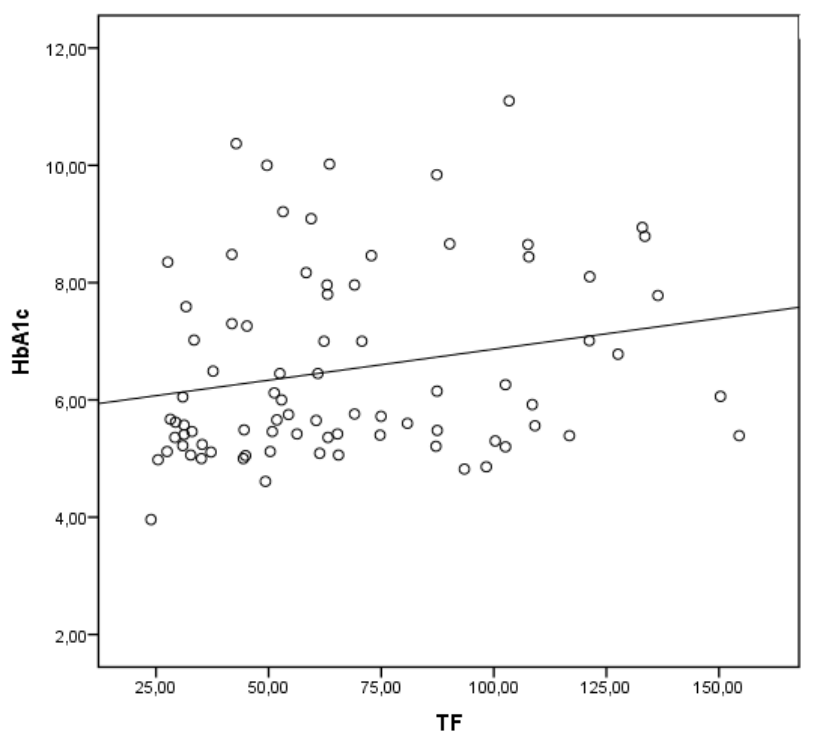

Figure 4: Correlation graph between TF and HbA1c. Serum levels of TF were correlated with serum levels of glucose $(r=0.226 ; p<0.05)$.

Wang et al. study found a positive correlation between TF levels and fasting insulin, glucose, and free fatty acids, as well as a positive correlation between adipose TF mRNA and plasma free fatty acids ${ }^{30}$. In another study, it was found that increasing the amount of insulin for 24 hours by keeping glucose at normal levels led to increased circulating TF activity and increasing glucose and insulin levels together led to a much more significant increase in TF activity, which is associated with larger increases in the thrombin-antithrombin complex (TAT) and prothrombin fragment $1+2(\mathrm{~F} 1+2)^{32}$. In the current study, no significant correlation was observed between serum TF activity and BMI. This was interpreted to mean that the existence of obesity alone may have only a limited effect on increasing TF activity. The results of the current study also demonstrated a positive correlation between TF activity, glucose, and HbA1c (Figure 3-4), and also provided evidence that hyperglycemia increases TF procoagulant activity ${ }^{32}$, and glycemic control leads to reduced circulating TF, especially in T2D ${ }^{37}$. Unlike the findings of the studies such as Vaidyula et al..$^{31}$ and Boden et al..$^{2}$, in recent studies demonstrated that hyperglycemia single-handedly influences TF. However, no correlation was found between TF and insulin levels. As for diabetic patients and diabetic patients with stroke, a positive correlation was found between hyperglycemia and $\mathrm{TF}^{38,39}$. Our study differs from these studies in that it reports a positive correlation between TF and HbA1c. It is known that the presence of advanced glycation end-products (AGE) increases $\mathrm{TF}^{40}$. 
In conclusion, a positive correlation was found between TF activity, and HbA1c and glucose levels. This suggests that TF may be predictive for diabetes which develop in the background of obesity, and that TF can be used as a prognostic value for diabetes. 


\section{REFERENCES}

1. Yigitbasi T, Emekli N. Obezite Biyokimyası. In Yiğitbaşı T. and Emekli N. (Ed.), Klinik Biyokimya (pp.311-321). İstanbul, 2015:Nobel Tip Kitabevleri.

2. Servan PR. Obesity and Diabetes. Nutr Hosp, 2013;28(5):138-43. https://doi.org/10.3305/ nh.2013.28.sup5.6929.

3. Ortug G, Ignak S, Ortug, A. Characteristics of lingual papillae in diabetic rats. Morphologie, 2018;102(339):250-254. https://doi.org/ 10.1016/j.morpho.2018.08.003.

4. Batirel S, \& Emekli N. Diabetes Mellitus ve laboratuvar. In Yiğitbaşı T. and Emekli N. (Ed.), Klinik Biyokimya (pp.159-173). İstanbul, 2015:Nobel Tip Kitabevleri.

5. Li S, Wang J, Zhang B, Li X, Liu Y. Diabetes Mellitus and cause-specific mortality: a population-based study. Diabetes Metab J, 2019;43(3):319-341.

6. https://doi.org/ 10.4093/dmj.2018.0060.

7. Rauch U, Nemerson Y. Circulating tissue factor and thrombosis. Curr Opin in Hematol, 2000;7:273-277. https://doi.org/10.4093/dmj.2018.006o.

8. Hisada Y, Mackman N. Tissue factor and cancer: regulation, tumor growth, and metastasis. Semin Thromb Hemost, 2019;45(4):385-395. https://doi.org/10.1055/s-0039-1687894.

9. Ruf W, Samad F. Tissue factor pathway linking obesity and inflammation. Hamostaseologie, 2015;35(3):279-283. https://doi.org/10.5482/HAMO-14-11-0068.

10. Badeanlou L, Furlan-Ferguia C, Yang G, Ruf W, Samad F. Tissue factor-protease-activated receptor 2 signaling promotes diet-induced obesity and adipose inflammation. Nat Med, 2011;17(11):1490-1497. https://doi.org/10.1038/nm.2461.

11. Cayrol C, Girard JP. Interleukin-33(IL-33): A nuclear cytokine from the IL-1 family. Immunol Rev, 2018;281(1):154-168. https://doi.org/10.1111/imr.12619.

12. Stojkovic S, Kaun C, Rauscher S, Hell, L, Krychtiuk KA, Bonstingl C. et al. Tissue factor is induced by interleukin-33 in human endothelial cells: a new link between coagulation and inflammation. Sci Rep, 2016;6:25171. https://doi.org/10.1038/srep25171.

13. Miller AM. Role of IL-33 in inflammation and disease. J Inflamm(Lond), 2011;8(1):22. https://doi.org/10.1186/1476-9255-8-22.

14. Gutin I. In BMI we trust: reframing the body mass index as a measure of health. Soc Theory Health, 2018;16(3):256-271. https://doi.org/10.1057/s41285-017-0055-0.

15. American Diabetes Association. Classification and diagnosis of diabetes: standards of medical care in diabetes-2019. Diabetes Care, 2019;42(1):13-28. https://doi.org/10.2337/dc19SoO2.

16. Matthews DR, Hosker JP, Rudenski AS, Naylor BA, Treacher DF, Turner RC. Homeostasis model assessment: insulin resistance and b-cell function from fasting plasma glucose and insulin concentrations in man. Diabetologia, 1985;28:412-419. https://doi.org/ 10.1007/ BFoO280883.

17. Hasan A, Kochuman S, Al-Ozair, E, Tuomiletho J, Ahmad R. Association between adipose tissue interleukin-33 and immunometabolic markers in individuals with varying degrees of glycemia. Dis Markers, 2019;2019:7901062. https://doi.org/ 10.1155/2019/7901062.

18. Griesenauer, B, Paczesny S. The ST2/IL-33 axis in immune cells during inflammatory diseases. Front Immunol, 2017;8:475. https://doi.org/10.3389/fimmu.2017.00475. 
19. Stojkovic S, Thulin A, Hell L, Thaler B, Rauscher S, Baumgartner J, et al. IL-33 stimulates the release of procoagulant microvesicles from human monocytes and differentially increases tissue factor in human monocyte subsets. Thromb Heamost, 2017;117(7):1379-90. https://doi. org/10.1160/TH16-10-0784.

20. Abuyassin B, Laher I. Obesity-linked diabetes in the arab World: a review. EMHJ, 2015;21(6):420-439. https://doi.org/10.26719/2015.21.420

21. Ayer JG, Song C, Steinbeck K, Celermajer DS, Freedman SB. Increased tissue factor activity in monocytes from obese young adults. Clin Exp Pharmacol Physiol, 2010;37(11):1049-1054. https://doi.org/10.1111/j.1440-1681.2010.05430.x.

22. Ay L, Kopp HP, Brix JM, Ay C, Quehenberger P, Schernthaner GH, et al. Thrombin generation in morbid obesity: significant reduction after weight loss. J Thromb Haemost, 2010;8(4):759-765. https://doi.org/10.1111/j.1538-7836.2010.03766.x.

23. Kopp CW, Kopp HP, Steiner S, Kriwanek S, Krzyzanowska K, Bartok A, et al. Weight loss reduces tissue factor in morbidly obese patients. Obes Res, 2003;11(8):950-956. https://doi. org/10.1038/oby.2003.131.

24. Singh A, Foster GD, Gunawardana J, McCoy TA, Nguyen T, Veur SV, et al. Elevated circulating tissue factor procoagulant activity, factor VII, and plasminogen activator inhibitor-1 in childhood obesity: evidence of a procoagulant state. Br J Haematol, 2012;158(4):523-527. https://doi: 10.1111/j.1365-2141.2012.09160.x.

25. 24- Samad F, Pandey M, Loskutoff DJ. Regulation of tissue factor gene expression in obesity. Blood, 2oo1;98:3353-3358. https://doi.org/10.1182/blood.V98.12.3353.

26. Zeyda M, Wernly B, Demyanets S, Kaun C, Hammerle M, Schranz M, et al. Severe obesity increases adipose tissue expression of interleukin-33 and its receptor ST2, both predominantly detectable in endothelial cells of human adipose tissue. Int J Obes (Lond), 2013;37(5):658665. https://doi.org/10.1038/ijo.2012.118.

27. Hasan A, Al-Ghimlas F, Warsame S, Al-Hubai A, Ahmad R, Bennakhi A, et al. IL-33 is negatively associated with the BMI and confers a protective lipid/metabolic profile in non-diabetic but not diabetic subjects. BMC Immunology, 2014;15:19. https://doi.org/ 10.1186/1471-217215-19.

28. Tang H, Liu N, Feng X, Yang Y, Zhuang S, Dai Y, et al. Circulating levels of IL-33 are elevated by obesity and positively correlated with metabolic disorders in Chinese adults. J Transl Med, 2021;19(1):52. https://doi: 10.1186/s12967-021-02711-x.

29. Miller AM. Role of IL-33 in inflammation and disease. J Inflamm (Lond), 2011;8(1):22. https://doi.org/10.1186/1476-9255-8-22.

30. Miller AM, Asquith DL, Hueber AJ, Anderson LA, Holmes WM, McKenzie AN, et al. Interleukin-33 induces protective effects in adipose tissue inflammation during obesity in mice. CircRes, 2010;107(5):650-658. https://doi.org/10.1161/CIRCRESAHA.110.218867.

31. Wang J, Ciaraldi, TP, Samad F. Tissue factor expression in obese type 2 diabetic subjects and its regulation by antidiabetic agents. J Obes, 2015;2015:291209. https://doi.org/ 10.1155/2015/291209.

32. Vaidyula VR, Rao AK, Mozzoli M, Homko C, Cheung P, Boden G. Effects of hyperglycemia and hyperinsulinemia on circulating tissue factor procoagulant activity and platelet CD40 ligand. Diabetes, 2006;55(1):202-208. https://doi.org/ 10.2337/diabetes.55.01.06.dbo5-1026. 
33. Boden G, Vaidyula VR, Homko C, Cheung P, Rao AK. Circulating tissue factor procoagulant activity and thrombin generation in patients with type 2 diabetes: effects of insulin and glucose. J Clin Endocrinol Metab, 2007;92(11):4352-4358. https://doi.org/10.1210/jc.2007-0933.

34. Gerrits AJ, Koekman CA, van Haeften TW, Akkerman JWN. Increased tissue factor expression in diabetes mellitus type 2 monocytes caused by insulin resistance. J Thromb Haemos, 2011;9(4):873-875. https://doi.org/10.1111/j.1538-7836.2011.04201.x.

35. Diamant M, Nieuwland R, Pablo RF, Sturk A, Smit JWA, Radder JK. Elevated numbers of tissue-factor exposing microparticles correlate with components of the metabolic syndrome in uncomplicated type 2 diabetes mellitus. Circulation, 2002;106(19):2442-2447. https://doi: 10.1161/01.cir.0000036596.59665.c6.

36. Vambergue A, Rugeri L, Gaveriaux V, Devos P, Martin A, Fermon C. et al. Factor VII, tissue factor pathway inhibitor, and monocyte tissue factor in diabetes mellitus: influence of type of diabetes, obesity index, and age. Thromb Res, 2001;101(5):367-374. https://doi: 10.1016/ so049-3848(00)00424-2.

37. Buchs AE, Kornberg A, Zahavi M, Aharoni D, Zarfati C, Rapoport M.J. Increased expression of tissue factor and receptor for advanced glycation end products in peripheral blood mononuclear cells of patients with type 2 diabetes mellitus with vascular complications. Exp Diabesity Res, 2004;5(2):163-169. https://doi: 10.1080/15438600490424325.

38. Sambol, A, Osende J, Hathcock J, Degen M, Nemerson Y, Fuster V. et al. Role of risk factors in the modulation of tissue factors activity and blood thrombogenicity. Circulation, 2003;107(7):973-977. https://doi.org/10.1161/01.CIR.0000050621.67499.7D.

39. Gentile NT, Vaidyula VR, Kanamalla U, DeAngelis M, Gaughan J, Rao AK. Factor VIIa and tissue factor procoagulant activity in diabetes mellitus after acute ischemic stroke: impact of hyperglycemia. Thromb Haemost, 2007;98(5):1007-1013. https://doi.org/10.116o/THo6-120719 .

40. Ichikawa K, Yoshinari M, Iwase M, Wakisaka M, Doi Y, Iino K, et al. Advanced glycosylation end products induced tissue factor expression in human monocyte like U937 cells and increased tissue factor expression in monocytes from diabetic patients. Atherosclerosis, 1998;136(2):281-287. https://doi.org/10.1016/Soo21-9150(97)00221-9.

41. Khechai F, Ollivier V, Bridey F, Amar M, Hakim J, de Prost D. Effect of advanced glycation end product-modified albumin on tissue factor expression by monocytes. Role of oxidant stress and protein tyrosine kinase activation. Arterioscler Thromb Vasc Biol 1997;17(11):2885-2890. https://doi.org/10.1161/o1.atv.17.11.2885. 